\title{
Some Effect of Chemical Treatment by Ferric Nitrate Salts on the Structure and Morphology of Coir Fibre Composites
}

\author{
Alveera Khan', Shirish Joshi', Mohammad Ayaz Ahmad², Vyacheslav Lyashenko ${ }^{3}$ \\ ${ }^{1}$ Physics Department, Motilal Vighyan Mahavidhyalaya, Bhopal, India \\ ${ }^{2}$ Physics Department, College of Science, University of Tabuk, Tabuk, Saudi Arabia \\ ${ }^{3}$ Laboratory "Transfer of Information Technologies in the Risk Reduction Systems", Kharkov National University \\ of Radioelectronics, Kharkov, Ukraine \\ Email: khanalveeera@gmail.com
}

Received 1 January 2015; accepted 16 January 2015; published 21 January 2015

Copyright (C) 2015 by authors and Scientific Research Publishing Inc.

This work is licensed under the Creative Commons Attribution International License (CC BY).

http://creativecommons.org/licenses/by/4.0/

(c) (i) Open Access

\begin{abstract}
The present study shows some important effects of chemical treatment on the structure and morphology of coir fibre. The objective of the present study is to optimise overall properties of coir fibre so as to use coir fibre as a reinforcing agent in thermoplastic and thermosetting polymers. In the present study, coir fibre is treated with ferric nitrate salt. A thermal treatment has been done at temperature of $1000^{\circ} \mathrm{C}$ by using annealing method. X-ray diffraction of the treated coir fibre reveals the crystalline nature of the fibre. Change in morphology has been found in coir fibre when subjected to scanning electron microscopy. Finally, the Fourier transform and infrared spectrographs show the presence of traces of iron oxide:fibre in the prepared composite.
\end{abstract}

\section{Keywords}

Annealing, Coir, SEM and XRD Analysis, Crystalline, Fibre

\section{Introduction}

Natural fiber reinforced polymer composites have to face many challenges in order to be commonly used as engineering materials [1]. As natural fibres are renewable in nature, so it can be a probable substitute for synthetic fibres in many applications where high strength is not needed [2]. Due to this, it is essential to illustrate and record the properties of these natural fibres and investigate new source of applications of fibres in composites. Coir fibre is a natural fibre found on the outer skull of coconut [3]. Coir fibre is one of the most widespread fi- 
bres among natural fibre found abundant in nature on cultivation [4]. As compared to other natural fibres, the substitution of coir fibre as reinforcing agent in polymer composites instead of synthetic fillers is not that easy due to its poor interfacial adhesion on thermosetting polymers [5]. Significant work has been done in turn to improve the potency of fibre-matrix interface [5]-[8]; however, a lot of work has yet to be done in order to assure the consistency of natural fibre composites.

Natural fibres are mainly required (next to cloth making) in the manufacture of composites. It is not only ecofriendly but also cost effective and durable. When compared to synthetic fillers such as glass, aramid, talc, and silica, natural fibres have a low density in many cases in comparison to synthetic fibres. Further, they do not leave any byproduct at the time of fabrication of composites because they are biodegradable in nature. In addition, these fibres can be processed at low temperature and therefore play a crucial role in energy investments for the production of composites [9]-[16].

The use of natural fibres as a reinforcing agent in polymer composites has been the centre of attraction among researchers during last so many years. The natural fibres are at a low density, and chemical treatments have been done, easy availability, renewable and biodegradable in nature. Though their use as a reinforcing agent is not much in vogue (because of their hydrophilic nature), their tendency to amass at the time of processing and their poor resistance to moisture [17]. In the present study, chemical treatments have been done for treating natural fibres so that their bonding with matrix can be improved by physical and chemical modification of fibre surface. This study extended parts of some other authors' work [1] in the field of coir fibres to find out some out some insights/differences.

In the present study, the main objective was to find effect of chemical treatment of coir fibre and see changes on the structure and morphology of fibre. It is clear from the obtained results that the chemically treated coir fibre is a reinforcing agent in polymer science and it is worth using as engineering materials in modern technology.

\section{Material and Method}

The fibre used for experimental study was taken from the temples of Bhopal.

\subsection{Processing of Coir Fibre}

The fibre used for experimental study was kept inside water for 24 hours and then washed so as to remove impurities like dust etc. After drying it, the chemical treatment was given.

\subsection{Chemical Treatment of Fibre}

Ferric nitrate (monohydrate, extra pure, $\left.\mathrm{Fe}\left(\mathrm{NO}_{3}\right)_{3} \cdot 9 \mathrm{H}_{2} \mathrm{O}\right)$ and ammonium chloride $\left(\mathrm{NH}_{4} \mathrm{Cl}\right)$ was taken in the ratio 10:4 in $500 \mathrm{ml}$ of distilled water. The mixture was stirred till a homogenous solution was obtained. In this mixture $10 \mathrm{~g}$ of processed coir fiber was added and then 1:1 solution of $\mathrm{NH}_{4} \mathrm{OH}$ (liquid ammonia) was added to it and left the solution for one hour. Again the mixture thus obtained was dried and then annealed in muffle furnace at $1000^{\circ} \mathrm{C}$ and kept it at that temperature for $15 \mathrm{~min}$.

The reaction may take place in this way

$$
\begin{aligned}
2 \mathrm{Fe}\left(\mathrm{NO}_{3}\right)_{3} \cdot 9 \mathrm{H}_{2} \mathrm{O}+3 \mathrm{NH}_{4} \mathrm{Cl}+3 \mathrm{NH}_{4} \mathrm{OH}+\text { Fiber } \rightarrow & \left.\mathrm{Fe}_{2} \mathrm{O}_{3} \text { : fiber(ferric oxide : fiber }\right)+6 \mathrm{NH}_{4} \mathrm{NO}_{3} \\
& +3 \mathrm{HOCl}+18 \mathrm{H}_{2} \mathrm{O}
\end{aligned}
$$

When ferric nitrate reacts with ammonium chloride and ammonium hydroxide along with coir fiber at $1000^{\circ} \mathrm{C}$ ferric oxide is formed which is confirmed through XRD analysis and other byproducts like $6 \mathrm{NH}_{4} \mathrm{NO}_{3}$ ammonium nitrate and $\mathrm{HOCl}$ (hypoclorous acid) decomposed at such high temperature and only ferric oxide is left.

\subsection{Nature and Structure of Sample after Firing}

The material formed was found to have the structure that of like sand crystals with holes in physical appearance. The sample appeared in powder form and it is rusty in color.

\subsection{Scanning Electron Microscope (SEM) Analysis}

The scanning electron microscope (SEM) images have been taken out from Japan made, JSM 6390A (JEOL Ja- 
pan) at dissimilar magnification of the above prepared samples. Before SEM examine the prepared samples were layered with gold in a vacuum coating unit. The cross section areas ranging of samples were approximately $1 \mathrm{~cm}$ to 5 microns in width and the magnification ranging of SEM was the order of $20 \times$ to approximately $30,000 \times$, with spatial resolution of 50 to $100 \mathrm{~nm}$.

\subsection{XRD Analysis}

The XRD measurements were carried out using Bruker D8, X-ray diffractometer. The X-rays were produced using a sealed tube and the wavelength of X-ray was $0.154 \mathrm{~nm}$, and also operated at $40 \mathrm{kV}$ and $100 \mathrm{~mA}$ with radiation source (CuK-alpha). The angle ( $2 \theta$ ) was scanned in the range of 5 to 80 at speed of $1.2 \mathrm{~min}^{-1}$.

\section{Results and Discussions}

\subsection{Results from SEM Analysis}

Figure 1(a) and Figure 1(b) show the scanning electron microscopy (SEM) analysis of untreated fibre and treated ones' fired at $1000^{\circ} \mathrm{C}$. One can notice from the above figures that there is change in the morphology of coir fibre before and after treatment. Uneven and cracked surface can be seen in the untreated samples which may be due to the presence of impurities in the fibre. The intercellular gaps which are seen in the untreated fibre were found to be less and there was change in the unevenness of the surface in contrast of treated fibre, it may be due to the chemical treatment done on the fibre. The variation in the surface of fibre is found due to chemical treatments and comparable behavior has been reported by some other researchers in their work [18] [19]. One finds that there is removal of surface impurities by chemical treatment which makes the fiber rough and that there was an increase in the surface area of fibre than that of raw fibre [20].

\subsection{Results from XRD Analysis of Treated Fibre}

The X-rays were detected by using a fast counting detector based on silicon strip technology (Bruker Lynx Eye detector). From the $\mathrm{X}$-ray diffraction study it is clear that treated fibre composites are crystalline in nature and shows the peaks of $\mathrm{Fe}_{2} \mathrm{O}_{3}$ [21].

The XRD pattern of the received composite is shown in Figure 2 the XRD spectra exhibits characteristic peaks at $2 \theta$ values of $24.2,33.2,35.7,40.9,49.5,44.5,47.1,54.1,52.7,57.6,62.5$, and 64.0 angstrom. It confirms the crystallinity of iron oxide fibre. Similar peaks of iron oxide have been observed by a researcher in his work [22] [23].

The XRD measurement of present samples has been shown in Figure 2 such as followings.

\subsection{FTIR Analysis}

The FTIR analysis of treated fibre has been depicted in Figure 3 such as followings.

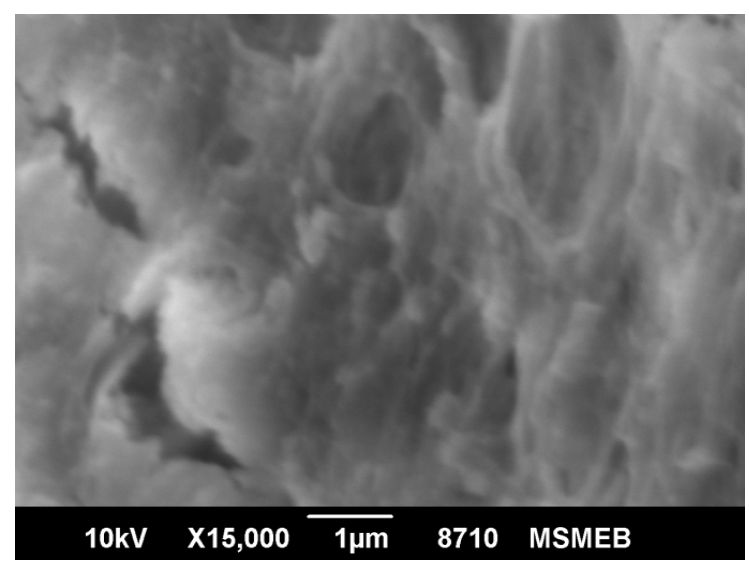

(a)

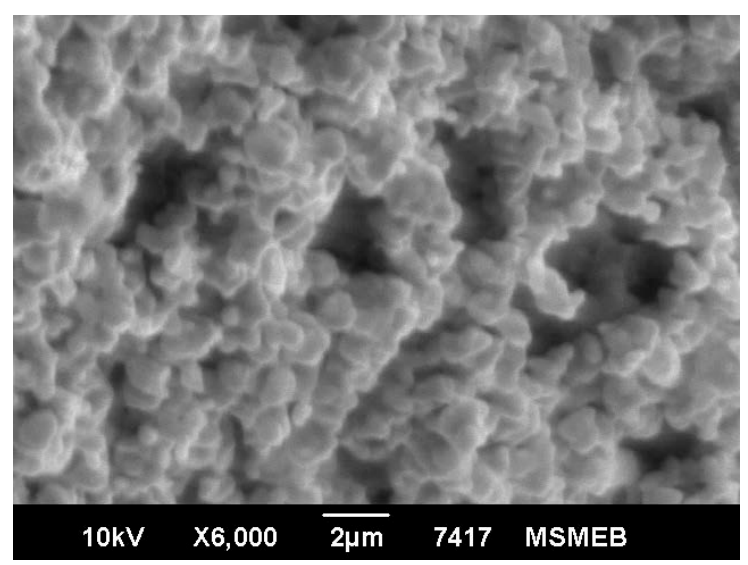

(b)

Figure 1. (a) SEM of untreated fibre; (b) SEM of treated fibre. 


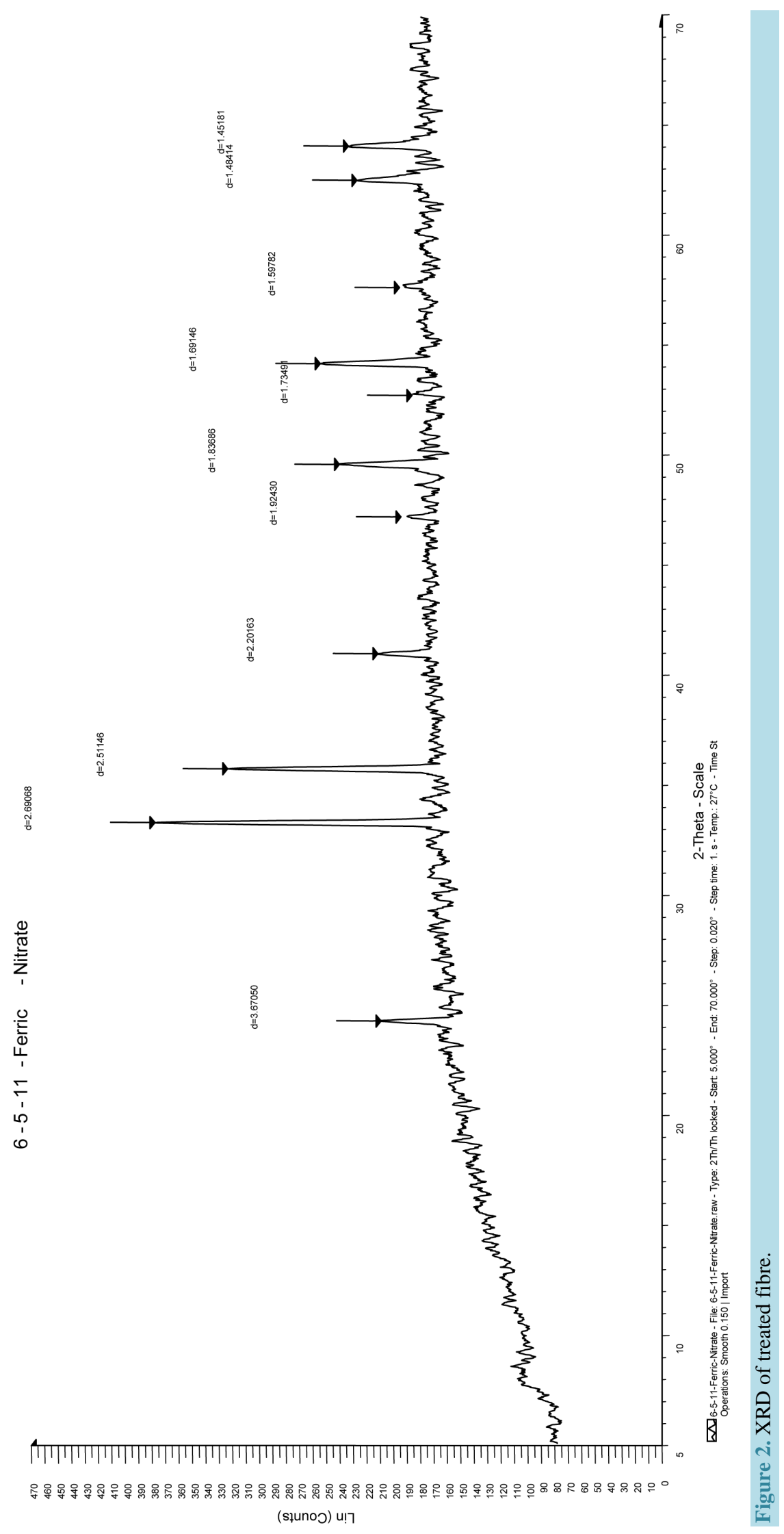




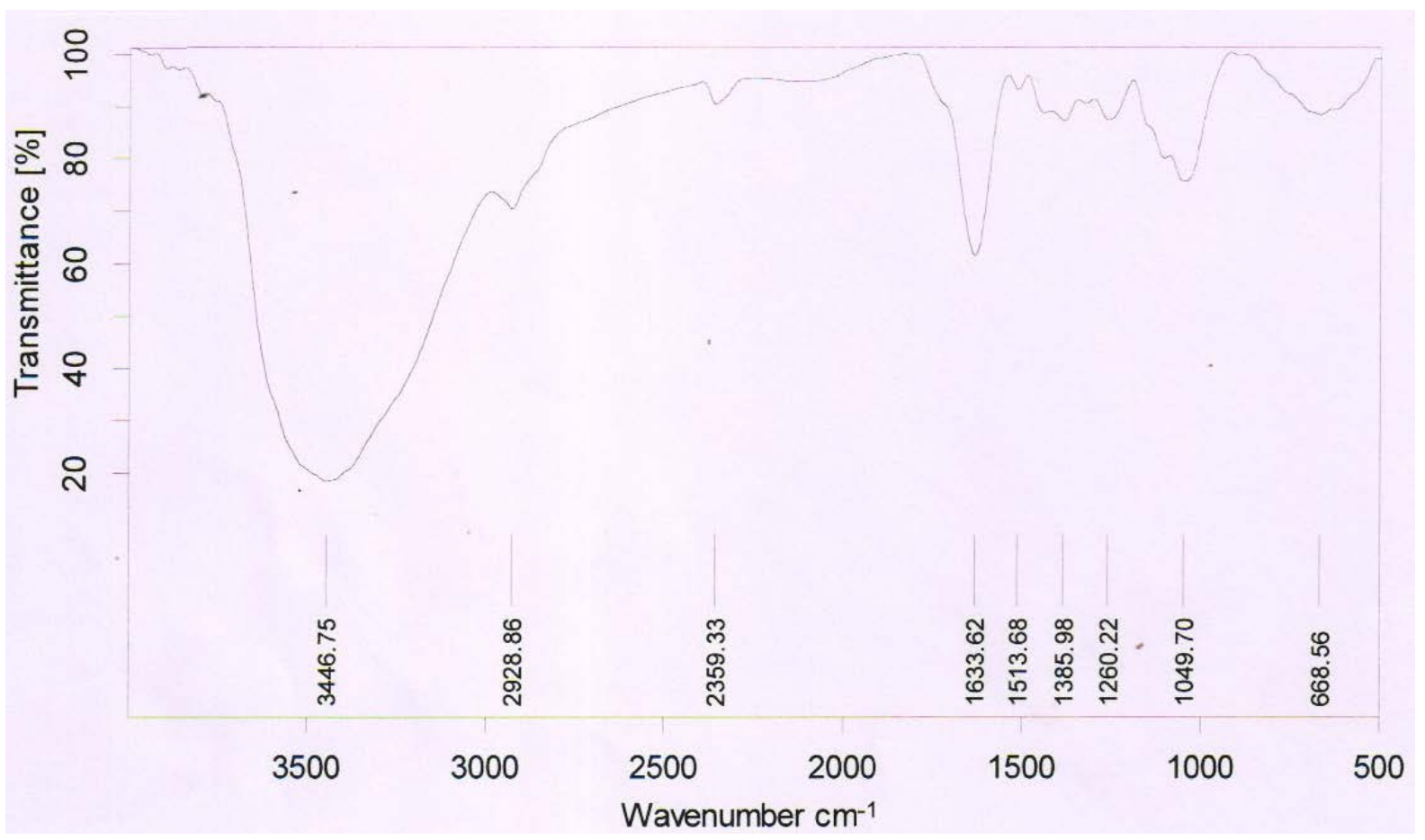

Figure 3. FTIR analysis of treated fibre.

From the FTIR analysis (Figure 3) the $3446 \mathrm{~cm}^{-1}$ broad intense absorption valley (low transmittance) in raw coir fibre is due to the O-H stretching for hydrogen-bonded hydroxyl group present in polysaccharide. It also indicates the broad \& strong band from cellulose, hemicelluloses and lignin of coir fibre. The weak peak occurs at $1386 \mathrm{~cm}^{-1}$ in raw coir fibre is due to the presence of hemicelluloses that can be assigned to the group of $\mathrm{C}=\mathrm{O}$ stretching. However the broad intense absorption at $1049 \mathrm{~cm}^{-1}$ is that of $(\mathrm{C}-\mathrm{OH})$. The absorption at $2928 \mathrm{~cm}^{-1}$ refers to Alkyl C-H group. The absorption at $2359 \mathrm{~cm}^{-1}$ refers to water. The absorption at $1633 \mathrm{~cm}^{-1}$ in raw coir is due to the $\mathrm{C}=\mathrm{C}$ aromatic skeletal ring vibration due to lignin [24]-[26].

Further, the FTIR study shows that when the coir fibre is treated by ferric nitrate salts there is a shift in the absorption from $3446 \mathrm{~cm}^{-1}$ to $3397 \mathrm{~cm}^{-1}$ which suggests that there is removal of impurities like lignin, cellulose and hemi-cellulose in the fibre [17] [27]. However the absorption at $2928 \mathrm{~cm}^{-1}$ shifts to $2958 \mathrm{~cm}^{-1}$ which may be due to the effect of chemical treatment done on coir fibre i.e., is there is change in the Alkyl C-H group. As well as there is change in the peak from $1633 \mathrm{~cm}^{-1}$ to $1635 \mathrm{~cm}^{-1}$ states that there is change in $\mathrm{C}=\mathrm{C}$ aromatic skeletal ring vibration due to lignin which again may be due to the chemical treatment on coir fibre. Again, minor change in absorptivity is seen for water from $2359 \mathrm{~cm}^{-1}$ to $2358 \mathrm{~cm}^{-1}$. However a broad valley at $556 \mathrm{~cm}^{-1}$ may refer to the Fe-O stretching and bending vibration mode of $\gamma-\mathrm{Fe}_{2} \mathrm{O}_{3}$. Similar results were reported by some authors [27] [28].

From above study it is clear that there is a trace of coir fibre in the sample in which there is an improvement in the removal of impurities in the fibre. However the peak at $556 \mathrm{~cm}^{-1}$ proposes the presence of $\gamma-\mathrm{Fe}_{2} \mathrm{O}_{3}$ in the sample. As a result, it can be concluded that there is successful synthesis of iron oxide $\left(\gamma-\mathrm{Fe}_{2} \mathrm{O}_{3}\right)$ fibre by annealing.

Finally, we were concluded the following discussions from the present experiment work:

A change in the morphology and structure has been found after the treatment of coir fibre which is confirmed by SEM technique.

The XRD analysis shows that treated coir fibre composites are crystalline in nature and shows the traces of $\gamma-\mathrm{Fe}_{2} \mathrm{O}_{3}$ :fibre.

Finally, the FTIR study also shows that when the coir fibre is treated by ferric nitrate salts there is a shift in the valley from $3446 \mathrm{~cm}^{-1}$ to $3397 \mathrm{~cm}^{-1}$ which suggests that there is removal of impurities like lignin, cellulose and hem-cellulose in the fibre. 


\section{Conclusions}

This study deals with the preparation of coir fibre composites with some new modification methods. Finally based upon the present study, one can draw the following conclusions:

It is clear that chemical treatment of coir fibre is an effective method to modify the properties of fibre. Change in the morphology of coir fibre has been seen through SEM analysis. An XRD study reveals the crystal structure of the samples. The FTIR study confirms the reduction of impurities from the fibre.

\section{Acknowledgements}

The authors are thankful to UGC-DAE Consortium, Indore for providing research facilities. The authors are also highly grateful to Vice Presidency for Graduate/Studies and Scientific Research at University of Tabuk, and Ministry of Higher Education, Kingdom of Saudi Arabia for the kind financial assistance.

\section{References}

[1] Calado, V., Barreto, D.W. and D’Almeida, J.R.M. (2000) The Effect of a Chemical Treatment on the Structure and Morphology of Coir Fibers. Journal of Material Science Letters, 19, 2151-2153. http://dx.doi.org/10.1023/A:1026743314291

[2] Mallick, P.K. (1993) Fibre Reinforced Composites: Materials, Manufacturing and Design. 2nd Edition, Marcel Dekker Inc., New York, 74.

[3] Harish, S., Peter Michael, D., Mohan Lal, D. and Rajadurai, A. (2009) Mechanical Property Evaluation of Natural Fiber Coir Composite. Material Characterization, 60, 44-49. http://dx.doi.org/10.1016/j.matchar.2008.07.001

[4] Venkataswamy, M.A., Pillai, C.S.K., Prasad, V.S. and Satyanarayana, K.G. (1987) Effect of Weathering on the Mechanical Properties of Midribs of Coconut Leaves. Journal of Material Science, 22, 3167-3172. http://dx.doi.org/10.1007/BF01161178

[5] Prasad, S.V., Pavithram, C. and Rohatgi, P.K. (1983) Alkali Treatment of Coir Fibres for Coir-Polyester Composites. Journal of Material Science, 18, 1443-1454. http://dx.doi.org/10.1007/BF01111964

[6] Mohanty, A.K. and Mishra, M. (1995) Biofibres, Biodegradable Polymers and Biocomposites: An Overview. Polymer Plastic Technology and Engineering, 34, 729-792. http://dx.doi.org/10.1080/03602559508009599

[7] Blezdki, A.K., Reihmane, S. and Gassan, J. (1996) Properties and Modification Methods for Vegetable Fibers for Natural Fiber Composites. Journal of Applied Polymer Science, 59, 1329-1336. http://dx.doi.org/10.1002/(SICI)1097-4628(19960222)59:8<1329::AID-APP17>3.0.CO;2-0

[8] Denes, F., Neilsen, L.D. and Young, R.A. (1997) Cold Plasma State-A New Approach to Improve Surface Adhesion in Lignocellulosic Plastics Composites. Lignocellulic Plastics Composites, 1, 61-110.

[9] Choi, N.W., Mori, I. and Ohama, Y. (2006) Development of Rice Husks-Plastics Composites for Building Materials. Waste Management, 26, 189-194. http://dx.doi.org/10.1016/j.wasman.2005.05.008

[10] Zeng, Z., Ren, W., Xu, C., Lu, W. and Zhang, Y. (2010) Maleated Natural Rubber Prepared through Mechanochemistry and Its Coupling Effects on Natural Rubber/Cotton Fiber Composites. Journal of Polymer Research, 17, $213-219$. http://dx.doi.org/10.1007/s10965-009-9307-6

[11] Thwe, M.M. and Liao, K. (2002) Effects of Environmental Aging on the Mechanical Properties of Bamboo-Glass Fiber Reinforced Polymer Matrix Hybrid Composites. Composites Part A: Applied Science and Manufacturing, 33, 4352. http://dx.doi.org/10.1016/S1359-835X(01)00071-9

[12] Yang, H.S., Kim, H.J., Son, J., Park, H.J., Lee, B.J. and Hwang, T.S. (2004) Rice-Husk Flour Filled Polypropylene Composites: Mechanical and Morphological Study. Composite Structures, 63, 305-312. http://dx.doi.org/10.1016/S0263-8223(03)00179-X

[13] Rana, A.K., Mandal, A. and Bandyopadhyay, S. (2003) Short Jute Fiber Reinforced Polypropylene Composites: Effect of Compatibiliser, Impact Modifier and Fiber Loading. Composites Science and Technology, 63, 801-806. http://dx.doi.org/10.1016/S0266-3538(02)00267-1

[14] Karmarkar, A., Chauhan, S.S., Modak, J.M. and Chanda, M. (2007) Mechanical Properties of Wood-Fiber Reinforced Polypropylene Composites: Effect of a Novel Compatibilizer with Isocyanate Functional Group. Composites Part A: Applied Science and Manufacturing, 38, 227-233. http://dx.doi.org/10.1016/j.compositesa.2006.05.005

[15] Teramoto, N., Urata, K., Ozawa, K. and Shibatal, M. (2008) Mechanical Properties of Polypropylene Composites Reinforced with Chemically Treated Coir and Abaca Fiber. Bioresource Technology, 99, 1474-1480.

[16] Rimduist, S., Wongsongyot, S., Jittarom, S., Suwanmala, P. and Tiptipakon, S. (2010) Effects of Gamma Irradiation 
with and without Compatibilizer on the Mechanical Properties of Polypropylene/Wood Flour Composites. Journal of Polymer Research, 18, 801-809. http://dx.doi.org/10.1007/s10965-010-9477-2

[17] Noorunnisa Khanam, P., Abdul Khalil, H.P.S., Jawaid, M., Ramachandra Reddy, G., Surya Narayana, C. and Venkata Naidu, S. (2010) Sisal/Carbon Fibre Reinforced Hybrid Composites: Tensile, Flexural and Chemical Resistance Properties. Journal of Polymers and the Environment, 18, 727-733. http://dx.doi.org/10.1007/s10924-010-0210-3

[18] Ariffuzaman Khan, G.M. and Shamsul Alam, Md. (2012) Thermal Characterization of Chemically Treated Coconut Husk Fibre. Indian Journal of Fibre \& Textile Research, 37, 20-26.

[19] Mullick, S.S. (2012) Fabrication and Characterization of Natural Fibre Reinforced Polymer Composites. Master Thesis, National Institute of Technology, Rourkela.

[20] Khan, M.A., Bhattacharia, S.K., Hassan, M.M. and Sultana, A. (2006) Effect of Pretreatment with Detergent on Mechanical Properties of Photocured Coir (Cocos nucifera) Fiber with Ethyleneglycol Dimethacrylate. Journal of Applied Polymer Science, 101, 1630-1636. http://dx.doi.org/10.1002/app.24026

[21] Khan, A. and Joshi, S. (2014) Mechanical and Morphological Study of Coir Fiber Treated with Different Nitro Compounds. International Journal of Advancement in Electronics and Computer Engineering, 2, 276-279.

[22] Zhao, B., Wang, Y., Guo, H., Wang, J., He, Y., Jiao, Z. and Wu, M. (2007) Iron Oxide(III) Nanoparticles Fabricated by Electron Beam Irradiation Method. Materials Science Poland, 25, 1143-1148.

[23] Wang, H.G., Li, Y.X., Sun, L., Li, Y.C., Wang, W., Wang, S.A., Xu, S.F. and Yang, Q.B. (2010) Electrospun Novel Bifunctional Magnetic-Photoluminescent Nanofibers Based on $\mathrm{Fe}_{2} \mathrm{O}_{3}$ Nanoparticles and Europium Complex. Journal of Colloid and Interface Science, 350, 396-401. http://dx.doi.org/10.1016/j.jcis.2010.06.068

[24] Choudhury, R. (2012) Fabrication and Characterization of Raw and Dewaxed Coir Fibre Reinforced Polymer Composites. E-Thesis, Department of Physics, National Institute of Technology, Rourkela.

[25] Samal, N. (2012) Fabrication and Characterization of Acetone Treated Natural Fibre Reinforced Polymer Composites. E-Thesis, Department of Physics, National Institute of Iechnology, Rourkela.

[26] Ahmad, Z., Sarifuddin, N., Iis, S. and Halim, Z. (2011) Effect of Fiber Length Variations on Mechanical and Physical Properties of Coir Fiber Reinforced Cement-Albument Composites (CFRCC). IIUM Engineering Journal, 12, 63-75.

[27] Kim, T., Nunnery, G.A., Jacob, K., Schwartz, J., Liu, X. and Tannenbaum, R. (2010) Synthesis, Characterization, and Alignment of Magnetic Carbon Nanotubes Tethered with Maghemite Nanoparticles. Journal of Physical Chemistry C, 114, 6944-6951. http://dx.doi.org/10.1021/jp9118925

[28] Sahoo, S.K., Agarwal, K., Singh, A.K., Polke, B.G. and Raha, K.C. (2010) Characterization of $\gamma$ - and $\alpha$-Fe $\mathrm{O}_{3} \mathrm{O}_{3} \mathrm{Nano}$ Powders Synthesized by Emulsion Precipitation-Calcination Route and Rheological Behaviour of $\alpha-\mathrm{Fe}_{2} \mathrm{O}_{3}$. International Journal of Engineering, Science and Technology, 2, 118-126. 
Scientific Research Publishing (SCIRP) is one of the largest Open Access journal publishers. It is currently publishing more than 200 open access, online, peer-reviewed journals covering a wide range of academic disciplines. SCIRP serves the worldwide academic communities and contributes to the progress and application of science with its publication.

Other selected journals from SCIRP are listed as below. Submit your manuscript to us via either submit@scirp.org or Online Submission Portal.
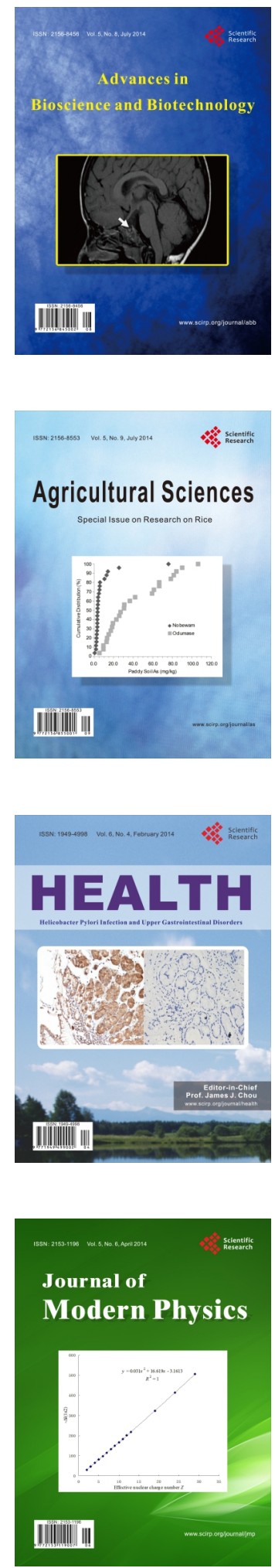
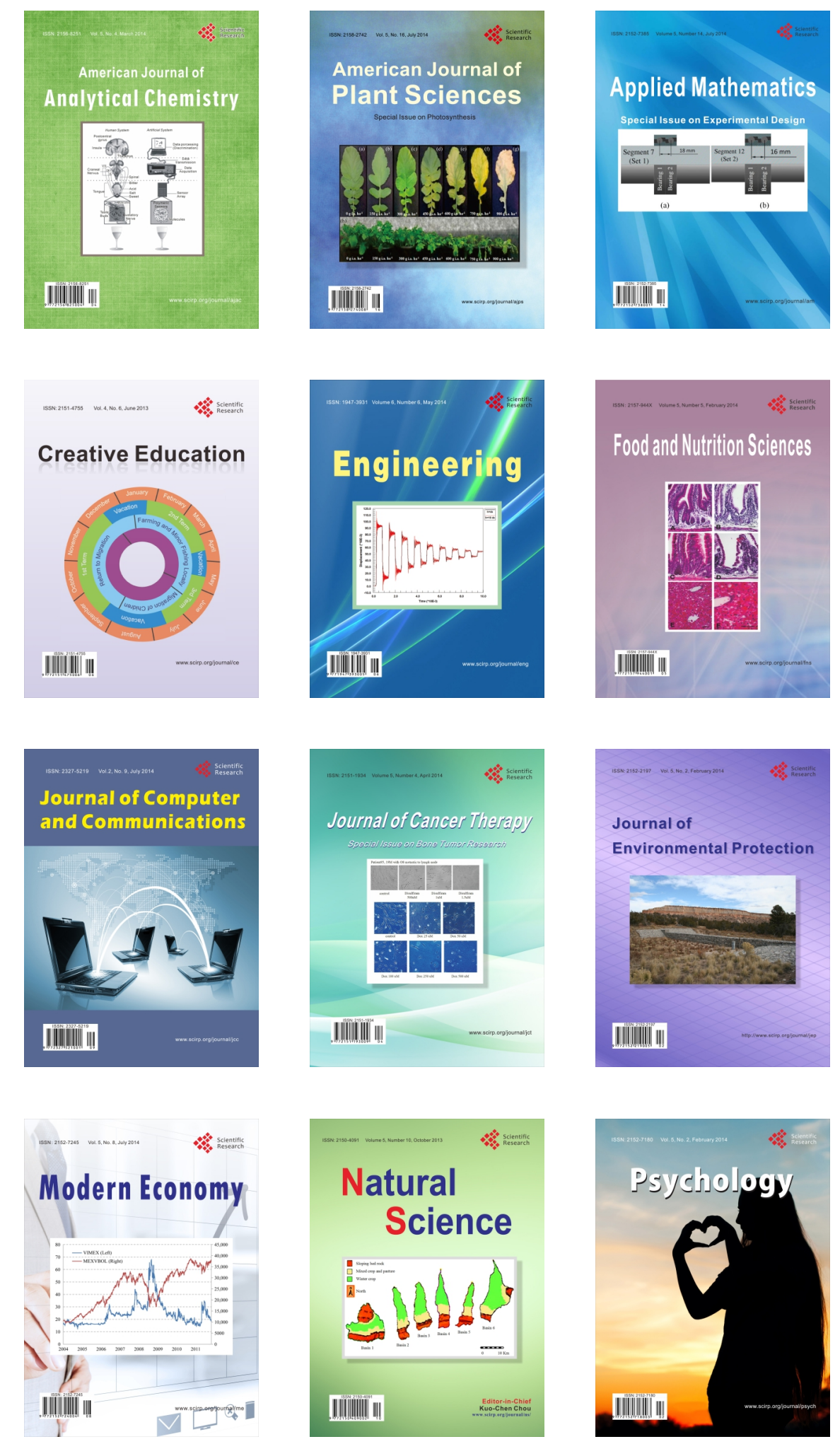